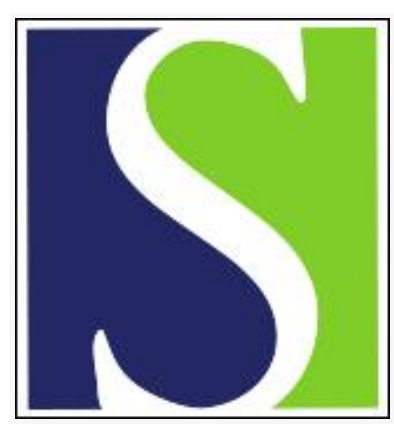

Scand J Work Environ Health 2006;32(3):225-240

https://doi.org/10.5271/sjweh.1003

Issue date: 30 Jun 2006

Tape-strip sampling for measuring dermal exposure to 1,6-hexamethylene diisocyanate

by Fent KW, Jayaraj K, Gold A, Ball LM, Nylander-French LA

Affiliation: Department of Environmental Sciences and Engineering, School of Public Health, The University of North Carolina at Chapel Hill, Rosenau Hall CB \#7431, Chapel Hill, NC 27599-7431, USA.

Key terms: 1,6-hexamethylene diisocyanate; dermal exposure; exposure assessment; sampling method; skin exposure; tape-strip sampling; tape-stripping

This article in PubMed: www.ncbi.nlm.nih.gov/pubmed/16804626 


\title{
Tape-strip sampling for measuring dermal exposure to 1,6-hexamethylene diisocyanate
}

\author{
by Kenneth W Fent, MS, ${ }^{1}$ Karupiah Jayaraj, PhD, ${ }^{1}$ Avram Gold, PhD, ${ }^{1}$ Louise M Ball, PhD, ${ }^{1}$ Leena A \\ Nylander-French, $P h D^{1}$
}

Fent KW, Jayaraj K, Gold A, Ball LM, Nylander-French LA. Tape-strip sampling for measuring dermal exposure to 1,6-hexamethylene diisocyanate. Scand J Work Environ Health 2006;32(3):225-231.

\begin{abstract}
Objectives This study describes the development and evaluation of a method for sampling layers of the stratum corneum for the quantitation of dermal exposure to 1,6-hexamethylene diisocyanate (HDI).

Methods HDI deposited on skin was collected by the removal of stratum corneum with adhesive tape, derivatized with 1-(2-methoxyphenyl)piperazine, and quantitated as the urea derivative (HDIU) by liquid chromatography-mass spectrometry (LC-MS). This LC-MS method was tested by analyzing tape spiked with HDI-containing products, then applied to tape samples collected from the skin of an auto-body shop worker exposed to polyurethane paint aerosols.

Results The limits of detection and quantitation were 20 and $50 \mathrm{fmol}$ per injection, respectively. The recovery of HDI from the tape was $99.3 \%$ [95\% confidence interval (95\% CI) $97.1-102$ ]. HDIU was stable at $-40^{\circ} \mathrm{C}$, degrading by $0.28 \%$ (95\% CI $0.10-0.46$ ) per day. Quantifiable amounts of HDI were observed in $42.6 \%$ of the first three successive tape-strip samples collected from 36 different sites on the skin of the worker. The amount of HDI recovered from the collection sites on skin, measured by summing the levels collected with three successive tape-strips, ranged from nondetectable to $1874 \mathrm{pmol}$.
\end{abstract}

Conclusions This study demonstrates that HDI on skin can be collected with tape-strips and quantified at occupational levels using LC-MS.

Key terms exposure assessment; sampling method; skin exposure; tape-stripping.

Aliphatic diisocyanates, such as 1,6-hexamethylene diisocyanate (HDI), are widely used in the production of polyurethane paints. Polyurethane paints are typically a mixture of base, containing pigments, alcohols, and other solvents, and hardener, containing solvents and monomeric and prepolymeric HDI. The monomer and prepolymer react with alcohols to form polyurethane (1). During spray-painting applications, some of the HDIcontaining aerosols are entrained in the airflow and are transported into the worker's working and breathing zone, where they can be inhaled or deposited on the skin (2). The HDI monomer [molecular weight (MW) 168] is more likely to penetrate the skin and become systemically available than compounds over MW 400 (3), such as many of the HDI oligomers (eg, biuret of HDI, MW 478), which are more abundant in paint.

A major health effect associated with diisocyanate exposure is asthma due to sensitization. An exposed worker can become sensitized after a single acute exposure; in most cases, sensitization occurs over a period of months to several years of exposure (4). Several studies describe diisocyanate exposure (5-8) and the occurrence of asthma (9-12) among workers in autobody shops. The major route of occupational exposure is thought to be inhalation of the vapor or aerosol; however, dermal exposure due to immersion, surface contact, or the deposition of aerosol or the uptake of vapor through the skin (13) may also constitute an important route of exposure. Dermal exposure to diisocyanates has been linked to allergic contact dermatitis in humans (1416) and respiratory sensitization in animals (17-19).

The quantitative analysis of dermal exposure generally uses patches or gloves for collection. Gloves and patches are, however, inadequate surrogates for skin, as they fail to provide information on the penetration of the chemical into the stratum corneum. The tape-strip

1 Department of Environmental Sciences and Engineering, University of North Carolina at Chapel Hill, Chapel Hill, North Carolina, United States.

Reprint requests to: Dr Leena Nylander-French, Department of Environmental Sciences and Engineering, School of Public Health, The University of North Carolina at Chapel Hill, Rosenau Hall CB \#7431, Chapel Hill, NC 27599-7431. [leena_french@unc.edu] 
technique, which has been used to measure dermal exposure to multifunctional acrylates, metals, and naphthalene (20-25), has the potential to quantify the amount of HDI that has penetrated into the stratum corneum, as well as the amount of HDI on the skin. An adhesive tape-strip is applied to the surface of the skin of an exposed worker. When removed, the tape-strip lifts off, on the average, one layer of corneocytes (26), including chemicals contained in the cell layer (20, 23-25). Hence successive tape-strips can serve to explore the extent of percutaneous penetration $(21,27)$.

Several existing air sampling methods [eg, method 5521 of the National Institute for Occupational Safety and Health (NIOSH) in the United States (28)], use liquid chromatography with ultraviolet or electrochemical detection. We substituted detection by mass spectrometry to improve the sensitivity and specificity of the analysis in a complex sample matrix, such as tape and skin.

The objective of our study was to develop a sensitive and specific method for quantifying dermal exposure to the HDI monomer by modifying NIOSH method 5521 for the liquid chromatography-mass spectrometry (LC-MS) analysis of tape samples and to evaluate this method in an occupational setting. Dermal exposure to HDI oligomers was not considered.

\section{Material and methods}

\section{Chemicals and supplies}

All of the solvents used in the study were HPLC (highpressure liquid chromatography) grade. Water was purchased from Fisher Scientific (Fair Lawn, NJ, USA). All other chemicals, unless otherwise specified, were obtained from Sigma Aldrich (St Louis, MO, USA). Gray camouflage base paint and hardener were supplied by Deft Incorporated (Irvine, CA, USA). Cover-Roll ${ }^{\circledR}$ adhesive tape, self-adhesive gauze with a woven polyester backing and polyacrylate adhesive, was obtained from Beiersdorf AG (Hamburg, Germany). This tape was selected because it has been successfully used to measure dermal exposure to other xenobiotics $(20,23-$ 25,27 ), and its chemical makeup does not contain compounds that interfere with the HDI analysis. Furthermore, Cover-Roll ${ }^{\circledast}$ was investigated under the product name Fixomull ${ }^{\circledR}$ (Beiersdorf AB, Kungsbacka, Sweden) along with several other types of tape and was found to perform the best during sampling and analysis and to give the most consistent removal efficiency for a multifunctional acrylate (ie, 85\% recovery from skin) (29).

\section{Instrumentation}

LC was performed on a Surveyor ${ }^{\circledR}$ LC system (Thermo Finnigan, Austin, TX, USA), equipped with an autosam- pler. A Thermo Finnigan Aquasil C18 column $(4.6 \times 50 \mathrm{~mm}, 3 \mu \mathrm{m}$ particle size $)$ with a Uniguard $^{\circledR}$ guard column was eluted with acetonitrile and $0.1 \%$ acetic acid in water at $1 \mathrm{ml} / \mathrm{min}$. The solvent composition was $20 \%$ acetonitrile during the first minute, increasing to $65 \%$ acetonitrile at 18 minutes, to $100 \%$ acetonitrile at 19 minutes, holding to 22 minutes, and returning to the original conditions at 24 minutes. The sample tray was maintained at $4^{\circ} \mathrm{C}$ and the column at $40^{\circ} \mathrm{C}$. Partialloop 10- $\mu \mathrm{l}$ injections were made with the use of an autosampler.

MS was performed on a Thermo Finnigan Surveyor $^{\circledR}$ quadrupole MS with an electrospray source operated in the positive ion mode. Nitrogen sheath gas (NG10LA nitrogen generator, Peak Scientific, Punta Gorda, FL, USA) was regulated at 22 psi (per square inch). The probe temperature and cone voltage were maintained at $575^{\circ} \mathrm{C}$ and $60 \mathrm{~V}$, respectively. Full scan data from 500 to 650 atomic mass units were collected for 24 minutes after injection with a scan time of 1.0 second. Between 10 and 20 minutes of the run, selective ion monitoring (SIM) was performed simultaneously at $\mathrm{m} / \mathrm{z} 553.4 \pm 0.5$ and $\mathrm{m} / \mathrm{z} 581.3 \pm 0.5$ to detect the protonated molecular ions of the urea derivatives of HDI (HDIU) and 1,8-octamethylene diisocyanate (ODIU), respectively.

\section{Preparation of standard solutions}

HDIU [MW 553; melting point $199-200^{\circ} \mathrm{C}$; literature $\left.199-200^{\circ} \mathrm{C}(28)\right]$ was synthesized by reacting HDI with 1-(2-methoxyphenyl)piperazine (MPP) according to NIOSH method 5521 (28). The same procedure was followed to synthesize ODIU (MW 581; melting point $185-188^{\circ} \mathrm{C}$ ) for use as an internal standard. The urea derivatives were characterized by $\mathrm{LC}-\mathrm{MS}$ and ${ }^{1} \mathrm{H}$ nuclear magnetic resonance $(500 \mathrm{MHz}$ Inova, Varian Inc, Palo Alto, CA, USA). HDIU and ODIU were $>98 \%$ pure according to their LC-MS total ion chromatograms.

HDIU was dissolved in methanol $(1 \mathrm{nmol} / \mu \mathrm{l})$ and diluted to $5,1,0.1,0.02$, and $0.01 \mathrm{pmol} / \mu \mathrm{l}$. ODIU was dissolved in methanol $(1 \mathrm{nmol} / \mu \mathrm{l})$, diluted to $2 \mathrm{pmol} / \mu \mathrm{l}$, and added (1:1 volume:volume) to the HDIU solutions to produce the standard solutions. This process was performed in triplicate to make three sets of standard solutions $(2.5,0.5,0.05,0.01$, and $0.005 \mathrm{pmol} / \mu \mathrm{l})$. Each standard solution had an internal standard concentration of $1 \mathrm{pmol} / \mu \mathrm{l}$. The standard curve compared the nominal HDIU concentration with the response ratio (ratio of the integrated HDIU and ODIU SIM chromatographic peaks).

\section{Preparation of samples}

The present method differs from NIOSH method 5521 with respect to sample preparation and detection. Whereas NIOSH method 5521 was intended for air 
sampling, tape was used as the collection medium in this study rather than an impinger filled with 15 milliliters of derivatizing solution ( $43 \mathrm{mg} / \mathrm{l} \mathrm{MPP} \mathrm{in} \mathrm{toluene).}$

With our present method, tape $\left(10 \mathrm{~cm}^{2}\right)$ was immersed in 4.8 milliliters of derivatizing solution $(2 \mathrm{~g} / \mathrm{l}$ MPP in methanol) at room temperature and immediately placed in a cooler $\left(\sim 4^{\circ} \mathrm{C}\right)$ until its return to the laboratory and storage at $-40^{\circ} \mathrm{C}$. Unlike NIOSH method 5521 , evaporation of the sampling medium and resuspension in $5 \mathrm{ml}$ of methanol was omitted. Residual MPP was acetylated as in NIOSH method 5521 by the addition of acetic anhydride $(100 \mu \mathrm{l})$ at room temperature, allowing 15 minutes for the reaction. Although NIOSH method 5521 did not specify an internal standard, 100 $\mu \mathrm{l}$ of ODIU in methanol $(50 \mathrm{pmol} / \mu \mathrm{l})$ was added to give an internal standard concentration of $1 \mathrm{pmol} / \mu \mathrm{l}$.

\section{Recovery of 1,6-hexamethylene diisocyanate from tape}

$\mathrm{HDI}$ on tape. HDI was dissolved in toluene $(10 \mathrm{nmol} / \mu \mathrm{l})$ and then diluted tenfold successively to $1000,100,10$, and $1 \mathrm{pmol} / \mu \mathrm{l}$. One sample was prepared by adding 50 microliters of the $100 \mathrm{pmol} / \mu \mathrm{l}$ solution to tape. Six other samples were prepared by adding either 25 or 50 microliters of each remaining solution to the tape. One additional sample was prepared by adding $12.5 \mathrm{mi}-$ croliters of the $1000 \mathrm{pmol} / \mu \mathrm{l}$ solution to the tape. These eight samples were prepared in triplicate, derivatized, and analyzed by LC-MS.

Hardener on tape. According to the material safety data sheet (MSDS), the hardener (Deft Inc) contains approximately $0.25 \%$ HDI $(\sim 15 \mathrm{nmol} / \mu \mathrm{l})$ (unpublished information). The hardener was dissolved in toluene to make a $20 \%$ by volume stock solution of hardener with an estimated HDI concentration of $3 \mathrm{nmol} / \mu \mathrm{l}$. This was diluted tenfold successively to $2,0.2$, and $0.02 \%$ hardener in toluene. Three samples were prepared by adding 200 microliters of each hardener solution to tape. Two additional samples were prepared by adding to tape 100 and 40 microliters of the $2 \%$ and $0.2 \%$ hardener solutions, respectively. The five samples were prepared in triplicate and then carried through the entire derivatization and analysis process. The absolute recovery of HDI could not be determined for these samples since the amount of HDI added to tape was estimated. A regression analysis was performed to evaluate the relationship between the amount of hardener added to tape and the average response ratio for each sample.

\section{Storage stability}

The stability of HDIU at $-40^{\circ} \mathrm{C}$ in different matrices was evaluated over a span of 3 weeks. To simulate the matrix most likely to be encountered in the work environment, 1 milliliter of hardener was combined with 3 mil- liliters of gray camouflage base paint (Deft Inc), drawn into a capillary tube and applied to five locations on a strip of tape ( $\sim 5 \mathrm{nmol}$ of HDI/spike). Two strips of tape were spiked with 25 and 50 microliters of 1000 and 100 $\mathrm{pmol} / \mu \mathrm{l}$ solutions of HDI in toluene, respectively. Two other tape strips were spiked with 100 and 200 microliters of $2 \%$ and $0.2 \%$ solutions of hardener in toluene, respectively. Approximately 30 minutes elapsed between the spiking of the tape and the immersion in the derivatization solution. Triplicates of each sample were made, and on the day of the analysis, fresh internal standard solution $(20 \mathrm{pmol} / \mu \mathrm{l})$ was prepared and combined (1:1 volume:volume ratio) with aliquots of each sample. The response ratio of HDIU over time was monitored.

\section{Occupational sampling}

We visited an auto-body shop twice in order to evaluate the tape-strip method in an occupational setting. In the shop, paint (Nason ${ }^{\circledR}$ DuPont, Wilmington, DE, USA) was applied with a conventional spray gun at a nozzle pressure of $60 \mathrm{psig}$ [pounds force of pressure per square inch gauge (excluding atmospheric pressure)] inside a temperature-controlled $\left(\sim 27^{\circ} \mathrm{C}\right)$ semi-downdraft enclosed booth. The worker spray-painting vehicles did not wear protective clothing or gloves but did wear a half-face respirator equipped with organic vapor cartridges. Overspray in the working zone was observed during all of the spray-painting tasks, especially when the worker was spraying upstream of the airflow.

Air samples were collected in the worker's breathing zone at $2 \mathrm{l} /$ minute using a high-flow pump and an ISO-CHEK $^{\circledR}$ sampler (SKC Inc, Eighty Four, PA, USA) if the sampling time was expected to be less than 15 minutes or an OSHA 42 glass fiber filter cassette (30) if the sampling time was expected to be more than 15 minutes. The pumps were calibrated before and after the sampling. The collected samples were stored in a cooler $\left(\sim 4^{\circ} \mathrm{C}\right)$ until the analysis by Galson Laboratories (East Syracuse, NY, USA).

Tape-strip sampling was performed after each paint task (three paint tasks during the first visit and four paint tasks during the second visit). Tape strips were applied to 14 sites on the hands, 16 sites on the arms, 5 sites on the neck, and 1 site on the forehead. Three successive tape-strips were collected on each of the 12 skin sites sampled during the first visit and five successive tape strips were collected on each of the 24 skin sites sampled during the second visit.

A fresh pair of gloves was used each time a tape strip was applied to or removed from the skin in order to prevent cross-contamination. Forceps cleaned with methanol were used to remove the tape strips and to place them in vials containing derivatizing solution. The 
vials were immediately placed inside a cooler $\left(\sim 4^{\circ} \mathrm{C}\right)$ for transport to the laboratory. The time between the sample collection and storage at $-40^{\circ} \mathrm{C}$ was less than 8 hours. The HDI content of the paint used for each task was recorded from the MSDS (Nason $\left.{ }^{\circledR}\right)$. For quality control assurance, tape and air-sample blanks were collected on site. The tape blanks included field blanks (unused tape) and sample blanks (tape applied to the worker's skin prior to beginning work).

\section{Statistical analysis}

The amount of HDI collected from each site on the skin was determined by summing the levels collected with three successive tape strips. The levels of HDI below the limit of quantitation (LOQ) and the first of successive tape samples to contain levels of HDI below the limit of detection (LOD) were assigned two-thirds of their respective limits as previously published (31).

Table 1. Analysis of 1,6-hexamethylene diisocyanate (HDI) in paint hardener applied to tape. (CV = coefficient of variation)

\begin{tabular}{lccc}
\hline $\begin{array}{l}\text { Hardener } \\
\text { added }(\mu \mathrm{l})^{\text {a }}\end{array}$ & $\begin{array}{c}\text { HDI in sample } \\
(\mathrm{pmol} / \mu \mathrm{l})\end{array}$ & $\% \mathrm{CV}$ & $\begin{array}{c}\text { HDI in hardener } \\
(\mathrm{nmol} / \mu \mathrm{l}) \mathrm{b}, \mathrm{c}\end{array}$ \\
\hline 0.04 & 0.04 & 3.6 & 10.4 \\
0.08 & 0.08 & 3.3 & 9.6 \\
0.40 & 0.44 & 3.5 & 11.1 \\
2.00 & 2.08 & 3.5 & 10.4 \\
4.00 & 4.20 & 1.1 & 10.5 \\
\hline
\end{tabular}

${ }^{a}$ Hardener applied to tape was carried through the derivatization and liquid chromatography-mass spectrometry analysis.

${ }^{b}$ On the basis of the information on the material safety data sheet, the concentration of $\mathrm{HDI}$ in hardener was estimated to be $15 \mathrm{nmol} / \mathrm{\mu l}$.

c The \% CV for measured HDI in hardener was 5.02.

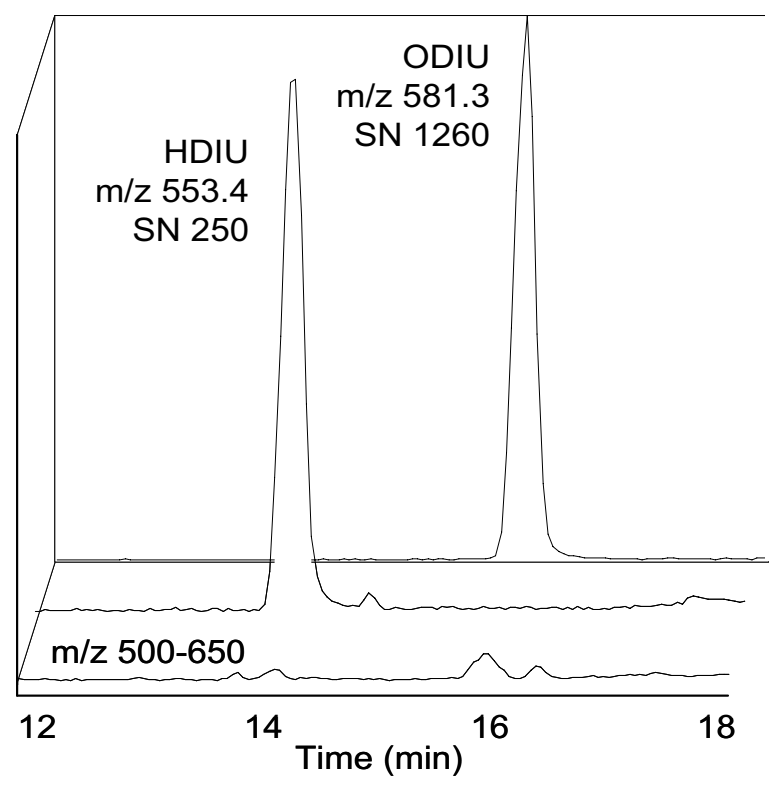

Figure 1. Chromatograms from the liguid chromatography - mass spectrometry analysis of the highest level tape sample (1039 pmol) collected from the spray painter's skin.
Summed values greater than two standard deviations above the mean $(>738 \mathrm{pmol})$ were identified as extreme and removed from the data set. The Shapiro-Wilks test for normality indicated that the dermal and inhalation exposure data were approximately log-normal $(\mathrm{W}=0.91$ and 0.84 , respectively). Statistical analyses were performed on log-transformed exposure data and with the SPSS 12.0 statistical package (SPSS Inc, Chicago, IL, USA).

\section{Results}

\section{Performance of the analytical method}

The correlation coefficient $\left(\mathrm{R}^{2}\right)$ between the nominal HDIU concentration and the average response ratio for the standard curve was $>0.999$ [standard error $(\mathrm{SE})=$ 0.11 ]. Concentrations were detectable at $2 \mathrm{fmol} / \mu \mathrm{l}$ [signal to noise ratio $\geq 3$ (32)] and quantifiable at $5 \mathrm{fmol} / \mu \mathrm{l}$. Thus the LOD and LOQ are 20 and $50 \mathrm{fmol}$ per injection, which correspond to 10 and 25.5 pmol per tape sample, respectively.

The precision of the analytical method was demonstrated through repeated injections of the standard solutions resulting in coefficients of variation of less than $5 \%$ (data not shown). The average recovery of HDI from tape was $99.3 \%$ [95\% confidence interval $(95 \% \mathrm{CI})$ 97.1-102\%]; therefore, this analytical method is also highly accurate. The nominal amounts of HDI spiked onto tape (ranging from $25 \mathrm{pmol}$ to $25 \mathrm{nmol}$ ) correlated well with the average response ratios $\left(\mathrm{R}^{2}>0.999, \mathrm{SE}=\right.$ 0.041 ).

Table 1 presents the analysis of HDI in hardener added to tape. The nominal quantity of hardener added to tape was highly correlated with the average response ratios $\left(\mathrm{R}^{2}>0.999, \mathrm{SE}=0.005\right)$. The response was linear over three orders of magnitude. The measured concentration of HDI in hardener varied by less than $5.1 \%$ across all of the analyzed samples.

\section{Storage stability}

The degradation of HDIU over a 3-week period was linear, averaging $0.28 \%$ (95\% CI $0.10-0.46 \%$ ) per day. On the average, the tape samples spiked with pure HDI were more stable (losing $0.17 \%$ per day) than the samples containing hardener (losing $0.38 \%$ per day) or paint (losing $0.33 \%$ per day) (results not shown).

\section{Occupational sampling}

Figure 1 demonstrates the selectivity that was achieved with LC-MS analysis by comparing the total and selective ion chromatograms for the highest-level tape sample $(1040 \mathrm{pmol})$ collected in the occupational setting. 
Despite the complex matrix for this sample, the full-scan mass spectra did not show extraneous ions in the regions of interest (data not shown).

A total of 36 different sites on the spray painter's skin were sampled. Levels collected with three successive tape strips were summed for each collection site on the skin and reported by region of skin (table 2). The levels of HDI recovered ranged from nondetectable to 1874 pmol. Of the 108 tape strips collected, 60 (55.5\%) contained detectable amounts and $46(42.6 \%)$ contained quantifiable amounts of HDI. The fourth and fifth successive tape strips $(\mathrm{N}=48)$ did not contain quantifiable amounts of HDI (data not shown). HDI was not detected in any of the blanks.

The air-sampling results are provided in table 3, along with other information collected for each paint task. Note that the levels collected from the neck and forehead were excluded from this table since these sites were not sampled during the first visit to the auto-body shop. A correlation matrix was generated using the variables (i) HDI recovered, (ii) painting time, (iii) breathing-zone concentration, (iv) HDI in paint-as well as the products of the latter two variables with painting time. This step was taken to determine if any of the variables collected can be used in predicting dermal exposure. Of the variables, the product of the breathing-zone concentration and painting time for each task was the most closely correlated $(r=0.47)$ with the amount of HDI recovered from the skin.

\section{Discussion}

The described tape-strip LC-MS method is capable of sampling layers of the stratum corneum for the determination of the HDI concentration on the skin. It is highly specific, employing selective ion monitoring and very sensitive, capable of detecting picomoles of HDI on tape. The LOD for NIOSH method 5521 with electrochemical detection is $500 \mathrm{fmol}$ per injection (28). Therefore, although the evaporation and resuspension step was omitted, our method (LOD $=20 \mathrm{fmol}$ per injection) is 25 times more sensitive than NIOSH method 5521.

The average recovery of HDI from tape $(99.3 \%)$ in our study compares favorably with that reported for impingers and filters in other studies $(28,33)$. The derivative is stable at $-40^{\circ} \mathrm{C}$ with an average daily degradation of $0.28 \%$. In comparison, NIOSH method 5521 reported an average degradation between $20 \%$ and $30 \%$ over 7 days at room temperature $(\sim 3.5 \%$ per day) and $11 \%$ over 7 days at $4^{\circ} \mathrm{C}(\sim 1.6 \%$ per day) (28). It is important to note that our samples may have degraded during the time between the collection and storage at $-40^{\circ} \mathrm{C}$. However, degradation is expected to be less than the 24- hour estimate at $4^{\circ} \mathrm{C}$ (ie, $\sim 1.6 \%$ ) since the samples were held at around this temperature for less than 8 hours.

The tape-strip method provides information regarding the distribution of HDI across the skin and the penetration of HDI through the stratum corneum. HDI was detected on successive tape strips, indicating possible penetration of HDI into the stratum corneum. Since the fourth or fifth successive tape strips did not contain quantifiable levels, summing the levels collected with the first three successive tape strips is suitable for estimating exposure on the site of skin sampled.

It cannot be excluded that some of the HDI may have penetrated into the deeper layers of the stratum corneum

Table 2.1,6-Hexamethylene diisocyanate (HDI) recovered with the first three successive tape strippings of the spray painter's skin ( $\mathrm{N}=$ number of skin sites, $\mathrm{GM}=$ geometric mean, $95 \% \mathrm{Cl}=$ 95\% confidence interval).

\begin{tabular}{lrrr}
\hline Skin region & $N$ & \multicolumn{2}{c}{ HDI recovered (pmol) a,b } \\
\cline { 3 - 4 } & & GM & $95 \% \mathrm{Cl}$ \\
\hline Arms & 16 & 51.3 & $31.0-84.8$ \\
$\quad$ Right & 8 & 80.0 & $38.7-166$ \\
Left & 8 & 32.8 & $16.3-66.2$ \\
Dorsal side & 10 & 55.6 & $26.2-118$ \\
$\quad$ Volar side & 6 & 44.8 & $19.2-104$ \\
Hands & 13 & 66.3 & $32.9-133$ \\
$\quad$ Right & 7 & 86.2 & $27.0-275$ \\
Left & 6 & 48.7 & $16.1-148$ \\
$\quad$ Neck & 5 & 9.0 & $4.0-20.4$ \\
Forehead & 1 & 33.9 & $\cdot$ \\
\hline All sites & $35{ }^{c}$ & 43.4 & $29.1-64.9$
\end{tabular}

a Summation of the levels recovered with three successive tape strips of each site sampled on the respective region of skin. Tape stripping was performed after each paint task.

b Levels below the limit of detection and limit of quantitation were assigned to two-thirds of their respective limits.

cxcludes one extreme value (1874 pmol) recovered from the hand.

Table 3.Factors contributing to overall 1,6-hexamethylene diisocyanate (HDI) exposure by paint task (GM = geometric mean, $95 \% \mathrm{Cl}=95 \%$ confidence interval, $\mathrm{N}=$ number of skin sites).

\begin{tabular}{|c|c|c|c|c|c|c|}
\hline \multirow[t]{2}{*}{$\begin{array}{l}\text { Paint } \\
\text { task }\end{array}$} & \multirow[t]{2}{*}{$\mathrm{N}$} & \multicolumn{2}{|c|}{$\begin{array}{l}\text { HDI recovered } \\
(\text { pmol })^{\mathrm{a}}\end{array}$} & \multirow{2}{*}{$\begin{array}{c}\text { Painting } \\
\text { time } \\
\text { (min) }\end{array}$} & \multirow{2}{*}{$\begin{array}{l}\text { HDI } \\
(\%) \text { in } \\
\text { paint }{ }^{b}\end{array}$} & \multirow{2}{*}{$\begin{array}{c}\mathrm{HDI} \text { in } \\
\text { breathing } \\
\text { zone } \\
\left(\mu \mathrm{g} / \mathrm{m}^{3}\right)\end{array}$} \\
\hline & & GM & $95 \% \mathrm{Cl}$ & & & \\
\hline 1 & 4 & 92.2 & $18.5-458$ & 15.0 & 0.010 & 13.2 \\
\hline 2 & 3 & 37.4 & $13.2-106$ & 19.0 & 0.025 & 5.2 \\
\hline 3 & 4 & 9.2 & $3.4-25.1$ & 6.5 & 0.020 & 5.2 \\
\hline 4 & 4 & 69.1 & $22.4-213$ & 12.0 & 0.022 & 2.5 \\
\hline 5 & 4 & 65.6 & $34.1-126$ & 13.5 & 0.018 & 5.5 \\
\hline 6 & 4 & 114 & $54.4-240$ & 10.0 & 0.010 & 12.9 \\
\hline 7 & 6 & 95.7 & $40.1-229$ & 18.5 & 0.018 & 10.6 \\
\hline
\end{tabular}

a Summation of the levels recovered with three successive tape strips of each site sampled on the arms and hands following a paint task (excludes levels recovered from the neck and forehead). Tape stripping was performed after each paint task.

b The proportion of HDI in paint by weight was estimated from the material safety data sheet. 
or reacted with macromolecules in the skin and therefore could not be collected or quantitated by the tapestrip method. Therefore, this method may underestimate dermal exposure. Furthermore, the evaporation of HDI from the skin may occur prior to tape-strip sampling. However, because evaporated HDI is not retained by the skin, it does not contribute to biologically relevant exposure to the skin.

Despite the small sample size in this study, interesting comparisons can be made between the amounts of HDI recovered from different regions of the skin. On the average, much less HDI was collected from the neck [geometric mean (GM) 9.0, 95\% CI 4.0-20.4 pmol, $\mathrm{N}=5$ ] than from the arms (GM 51.3, 95\% CI $31.0-84.8$ pmol, $\mathrm{N}=16, \mathrm{P}=0.001)$ and hands $(\mathrm{GM}=66.3,95 \% \mathrm{CI}$ 32.9-133 pmol, $\mathrm{N}=13, \mathrm{P}=0.002$ ). One possible reason for these differences may be that more of the overspray was pulled across the anterior side of the body than the posterior side of the body (ie, back of the neck). Carlton \& England (1) observed that, when a spray painter's back or sides are perpendicular to the airflow, exposure to overspray is reduced by freestream capture; however, when a painter is facing the airflow, exposure to overspray is amplified and directed toward the anterior side of the body.

Even when the worker's sides are perpendicular to the airflow, semi-downdraft booths may pull contaminated air across the body of the worker. This is especially true with conventional spray guns (like the one used in this study) because the momentum of particles generated at nozzle pressures above 20 psig is sufficient to produce overspray upstream of the airflow (2). Thus the right arm and hand of the worker holding the spray gun are expected to have greater exposures from deposition than the left arm and hand. Indeed, on the average, more HDI was collected from the right arm (GM 80.0, 95\% CI 38.7-166 pmol, $\mathrm{N}=8$ ) and hand (GM 86.2, 95\% CI 27.0-275 pmol, N=7) than the left arm (GM 32.8 , 95\% 16.3-66.2 pmol, $\mathrm{N}=8, \mathrm{P}=0.038$ ) and hand (GM 48.7, 95\% CI 16.1-148 pmol, $\mathrm{N}=6, \mathrm{P}=0.400$ ).

It is important to note that the exposure to the right hand does not differ significantly $(\mathrm{P}<0.05)$ from that of the left hand. This similarity may be due to the lack of statistical power or there may be another competing mechanism of exposure to the hands, such as splashing or direct transfer during the mixing process. Splashing or direct transfer would explain why four of the five highest levels of HDI were recovered from the hands of the worker. The distribution of exposure across the body underscores the importance of wearing gloves and protective clothing during both the mixing and application of paint.

Personal air sampling was performed only when HDI-containing paint was being applied. Therefore, the breathing-zone concentrations represent task-based time-weighted averages (TWA) rather than shift-based (8-hour) TWA. The breathing-zone concentrations for each of the seven paint tasks ranged from 2.5 to 13.2 $\mu \mathrm{g} / \mathrm{m}^{3}$ with a mean of $7.9 \mu \mathrm{g} / \mathrm{m}^{3}$. These concentrations overestimate the amount that is actually inhaled since the half-face respirator worn by the worker provides some level of protection against airborne HDI exposure. At a reasonably anticipated protection factor for the respirator, the dermal pathway may be the primary route of exposure for the worker in this study. Other studies have reported similar or higher task-based breathingzone concentrations of HDI, ranging from 3.05 to 53.1 $\mu \mathrm{g} / \mathrm{m}^{3}$ with a mean of $15.5 \mu \mathrm{g} / \mathrm{m}^{3}(\mathrm{~N}=57)$ measured by the NIOSH 5521 sampling method, and from 1.00 to 102 $\mu \mathrm{g} / \mathrm{m}^{3}$ with a mean of $17.5 \mu \mathrm{g} / \mathrm{m}^{3}(\mathrm{~N}=45)$ measured by the ISO-CHEK sampling method (1).

Although there have been numerous airborne diisocyanate exposure assessments in the automotive refinishing industry, only one study, to our knowledge, has addressed dermal diisocyanate exposure. That study was qualitative in nature and, as such, the correlation of dermal exposure with other factors was not investigated (34). In our study, dermal exposure, measured with tapestrip sampling, was correlated with the product of breathing-zone concentration and painting time. Thus dermal exposure may be estimated or modeled on the basis of air measurements and possibly using other information such as spray nozzle pressure, air temperature, ventilation type, and flow rate.

This study demonstrates that tape-strip sampling can be used to quantify dermal exposure to HDI for autobody shop workers who perform spray-painting. An advantage of this method, compared with surrogate and other removal techniques, is that it provides a way of measuring exposure on or within the skin and provides a means with which to investigate percutaneous penetration. Our findings indicate that dermal exposure to HDI is likely in the automotive refinishing industry, especially in the absence of protective clothing, and is correlated with inhalation exposure.

\section{Acknowledgments}

This study was approved by the Institutional Review Board in the Office of Human Research Ethics at the University of North Carolina at Chapel Hill and was supported by grants from the National Institute for Occupational Safety and Health (R01-OH007598 and T42/ CCT422952) and the National Institute of Environmental Health Sciences (P30ES10126).

The authors are grateful to the auto-body shop worker who volunteered to participate in this study, to Chris Trent and Roxana Vega for contributing to the method 
development, and to Dr Yutai Li for assisting with the LC-MS analysis.

\section{References}

1. Carlton GN, England EC. Exposures to 1,6-hexamethylene diisocyanate during polyurethane spray painting in the U.S. Air Force. Appl Occup Environ Hyg. 2000;15:705-12.

2. Carlton GN, Flynn MR. A model to estimate worker exposure to spray paint mists. Appl Occup Environ Hyg. 1997;12:375382.

3. Marzulli FN, Anjo DM, Maibach HI. In vivo skin penetration studies of 2,4-toluenediamine, 2,4-diaminoanisole, 2-nitro-pphenylenediamine, $\mathrm{p}$-dioxane and $\mathrm{N}$-nitrosodiethanolamine in cosmetics. Food Cosmet Toxicol. 1981;19:743-7.

4. Chan-Yeung M, Lam S. Occupational asthma. Am Rev Respir Dis. 1986;133:686-703.

5. Janko M, McCarthy K, Fajer M, van Raalte J. Occupational exposure to 1,6-hexamethylene diisocyanate-based polyisocyanates in the state of Oregon, 1980-1990. Am Ind Hyg Assoc J. 1992;53:331-8.

6. Pisaniello DL, Muriale L. The use of isocyanate paints in auto refinishing - a survey of isocyanate exposures and related work practices in South Australia. Ann Occup Hyg. 1989;33:563-72.

7. Lesage J, Goyer N, Desjardins F, Vincent JY, Perrault G. Workers' exposure to isocyanates. Am Ind Hyg Assoc J. 1992;53:146-53.

8. Rudzinski WE, Dahlquist B, Svejda SA, Richardson A, Thomas T. Sampling and analysis of isocyanates in spray-painting operations. Am Ind Hyg Assoc J. 1995;56:284-289.

9. Piirilä PL, Nordman H, Keskinen HM, Luukkonen R, Salo SP, Tuomi TO, et al. Long-term follow-up of hexamethylene diisocyanate-, diphenylmethane diisocyanate-, and toluene diisocyanate-induced asthma. Am J Respir Crit Care Med. 2000;162:516-22.

10. Cockcroft DW, Mink JT. Isocyanate-induced asthma in an automobile spray painter. Can Med Assoc J. 1979;121:602-4.

11. Belin L, Hjortsberg U, Wass U. Life-threatening pulmonary reaction to car paint containing a prepolymerized isocyanate [letter to the editor]. Scand J Work Environ Health. 1981;7:310-1.

12. Malo JL, Ouimet G, Cartier A, Levitz D, Zeiss CR. Combined alveolitis and asthma due to hexamethylene diisocyanate (HDI), with demonstration of crossed respiratory and immunologic reactivities to diphenylmethane diisocyanate (MDI). J Allergy Clin Immunol. 1983;72:413-9.

13. Fenske RA. Dermal exposure assessment techniques. Ann Occup Hyg. 1993;37:687-706.

14. Kanerva L, Lähteenmäki M, Estlander T, Jolanki R, Keskinen H. Current topics in contact dermatitis. New York (NY): Springer; 1989.

15. Wilkinson SM, Cartwright PH, Armitage J, English JS. Allergic contact dermatitis from 1,6-diisocyanatohexane in an antipill finish. Contact Dermatitis. 1991;25:94-6.

16. Morgan CJ, Haworth AE. Allergic contact dermatitis from 1,6-hexamethylene diisocyanate in a domestic setting. Contact Dermatitis. 2003;48:224.

17. Karol MH, Hauth BA, Riley EJ, Magreni CM. Dermal contact with toluene diisocyanate (TDI) produces respiratory tract hypersensitivity in guinea pigs. Toxicol Appl Pharmacol. 1981;58:221-30.
18. Herrick CA, Xu L, Wisnewski AV, Das J, Redlich CA, Bottomly K. A novel mouse model of diisocyanate-induced asthma showing allergic-type inflammation in the lung after inhaled antigen challenge. J Allergy Clin Immunol. 2002;109:873-8.

19. Rattray NJ, Botham PA, Hext PM, Woodcock DR, Fielding I, Dearman RJ, et al. Induction of respiratory hypersensitivity to diphenylmethane-4,4'-diisocyanate (MDI) in guinea pigs. Influence of route of exposure. Toxicology. 1994;88:15-30.

20. Nylander-French LA. A tape-stripping method for measuring dermal exposure to multifunctional acrylates. Ann Occup Hyg. 2000;44:645-51.

21. Hostynek JJ, Dreher F, Pelosi A, Anigbogu A, Maibach HI. Human stratum corneum penetration by nickel. In vivo study of depth distribution after occlusive application of the metal as powder. Acta Derm Venereol Suppl (Stockh). 2001:5-10.

22. Cullander C, Grant PG, Bench G. Development of a lowmetal adhesive tape to detect and localize metals in or on the stratum corneum at parts per million levels. Skin Pharmacol Appl Skin Physiol. 2001;14 Suppl 1:46-51.

23. Chao YC, Gibson RL, Nylander-French LA. Dermal exposure to jet fuel (JP-8) in US Air Force personnel. Ann Occup Hyg. 2005;49:639-45.

24. Chao YC, Kupper LL, Serdar B, Egeghy PP, Rappaport SM, Nylander-French LA. Dermal exposure to jet fuel JP-8 significantly contributes to the production of urinary naphthols in fuel-cell maintenance workers. Environ Health Perspect. 2006;114:182-5.

25. Chao YC, Nylander-French LA. Determination of keratin protein in a tape-stripped skin sample from jet fuel exposed skin. Ann Occup Hyg. 2004;48:65-73.

26. Schwindt DA, Wilhelm KP, Maibach HI. Water diffusion characteristics of human stratum corneum at different anatomical sites in vivo. J Invest Dermatol. 1998;111:385-9.

27. Kim D, Andersen ME, Nylander-French LA. Dermal absorption and penetration of jet fuel components in humans. Toxicol Lett. In press.

28. National Institute for Occupational Safety and Health (NIOSH). Method 5521, isocyanates, monomeric, issue 2. In: Eller PM, Cassinelli ME, editors. NIOSH Manual of Analytical Methods. 4th ed. Cincinnati (OH): NIOSH; 1994.

29. Surakka J, Johnsson S, Rosen G, Lindh T, Fischer T. A method for measuring dermal exposure to multifunctional acrylates. J Environ Monit. 1999;1:533-40.

30. Occupational Safety and Health Administration (OSHA). Diisocyanates: method 42. OSHA sampling \& analytical methods. Salt Lake City (UT): US Department of Labor, OSHA; 1983.

31. Nylander-French LA, Kupper LL, Rappaport SM. An investigation of factors contributing to styrene and styrene-7,8-oxide exposures in the reinforced-plastics industry. Ann Occup Hyg. 1999;43:99-105.

32. Skoog D, Leary J. Principles of Instrumental Analysis. 4th ed. Orlando (FL): Harcourt Brace College Publishers; 1992.

33. Bello D, Streicher RP, Woskie SR. Evaluation of the NIOSH draft method 5525 for determination of the total reactive isocyanate group (TRIG) for aliphatic isocyanates in autobody repair shops. J Environ Monit. 2002;4:351-60.

34. Liu Y, Sparer J, Woskie SR, Cullen MR, Chung JS, Holm CT, et al. Qualitative assessment of isocyanate skin exposure in auto body shops: a pilot study. Am J Ind Med. 2000;37:26574.

Received for publication: 7 July 2005

Scand J Work Environ Health 2006, vol 32, no 3 